\title{
Long-term follow-up and quality of life
} in patients receiving extracorporeal membrane oxygenation for pulmonary embolism and cardiogenic shock

\author{
Andrea Stadlbauer ${ }^{1 *} \mathbb{0}$, Alois Philipp ${ }^{1}$, Sebastian Blecha ${ }^{2}$, Matthias Lubnow ${ }^{3}$, Dirk Lunz ${ }^{2}$, Jing Li ${ }^{1}$, \\ Armando Terrazas ${ }^{1}$, Christof Schmid ${ }^{1}$, Tobias J. Lange ${ }^{3+}$ and Daniele Camboni ${ }^{1 \dagger}$
}

\begin{abstract}
Background: Since 2019, European guidelines recommend considering extracorporeal life support as salvage strategy for the treatment of acute high-risk pulmonary embolism (PE) with circulatory collapse or cardiac arrest. However, data on long-term survival, quality of life (QoL) and cardiopulmonary function after extracorporeal membrane oxygenation (ECMO) are lacking.

Methods: One hundred and nineteen patients with acute PE and severe cardiogenic shock or in need of mechanical resuscitation (CPR) received venoarterial or venovenous ECMO from 2007 to 2020. Long-term data were obtained from survivors by phone contact and personal interviews. Follow-up included a QoL analysis using the EQ-5D-5L questionnaire, echocardiography, pulmonary function testing and cardiopulmonary exercise testing.

Results: The majority of patients $(n=80,67 \%)$ were placed on ECMO during or after CPR with returned spontaneous circulation. Overall survival to hospital discharge was $45.4 \%$ (54/119). Nine patients died during follow-up. At a median follow-up of 54.5 months (25-73; $56 \pm 38$ months), 34 patients answered the QoL questionnaire. QoL differed largely and was slightly reduced compared to a German reference population (EQ5D5L index $0.7 \pm 0.3$ vs. $0.9 \pm 0.04$; $p<0.01)$. 25 patients (73.5\%) had no mobility limitations, 22 patients (65\%) could handle their activities, while anxiety and depression were expressed by 10 patients (29.4\%). Return-to-work status was 33.3\% (average working hours: $36.2 \pm 12.5 \mathrm{~h}$ /per week), 15 (45.4\%) had retired from work early. 12 patients (35.3\%) expressed limited exercise tolerance and dyspnea. 59\% (20/34) received echocardiography and pulmonary function testing, 50\% (17/34) cardiopulmonary exercise testing. No relevant impairment of right ventricular function and an only slightly reduced mean peak oxygen uptake (76.3\% predicted) were noted.
\end{abstract}

Conclusions: Survivors from severe intractable PE in cardiogenic shock or even under CPR with ECMO seem to recover well with acceptable QoL and only minor cardiopulmonary limitations in the long term. To underline these results, further research with larger study cohorts must be obtained.

Keywords: ECMO, Pulmonary embolism, Quality of life

*Correspondence: andrea.stadlbauer@ukr.de

†Tobias J. Lange and Daniele Camboni contributed equally to this work ${ }^{1}$ Department of Cardiothoracic Surgery, University Medical Center Regensburg, Franz-Josef-Strauss-Allee 11, 93053 Regensburg, Germany Full list of author information is available at the end of the article

\section{Background}

Despite growing scientific insights and constantly evolving therapeutic strategies, pulmonary embolism (PE) still poses a threat to patients of all ages.

\section{Springer Open}

(c) The Author(s) 2021. Open Access This article is licensed under a Creative Commons Attribution 4.0 International License, which permits use, sharing, adaptation, distribution and reproduction in any medium or format, as long as you give appropriate credit to the original author(s) and the source, provide a link to the Creative Commons licence, and indicate if changes were made. The images or other third party material in this article are included in the article's Creative Commons licence, unless indicated otherwise in a credit line to the material. If material is not included in the article's Creative Commons licence and your intended use is not permitted by statutory regulation or exceeds the permitted use, you will need to obtain permission directly from the copyright holder. To view a copy of this licence, visit http://creativecommons.org/licenses/by/4.0/. 
The incidence of PE in the European Union is estimated at $0.95 / 1000$ population per year [1]. Depending on the severity of vessel obstruction and right heart strain, clinical manifestations range from mild symptoms to sudden cardiac death.

Acute high-risk PE, defined as PE with sustained hypotension (systolic blood pressure (SBP) $<90 \mathrm{mmHg}$ or pressure drop $>40 \mathrm{mmHg}$ for $\geq 15 \mathrm{~min}$ ), obstructive shock (SBP $<90 \mathrm{mmHg}$ or need for vasopressors, and end-organ hypoperfusion), or cardiac arrest, is associated with a mortality of $25 \%$ in patients with cardiogenic shock and up to $65 \%$ for those requiring cardiopulmonary resuscitation (CPR) [2, 3].

Therapeutic strategies include reperfusion via anticoagulation, thrombolysis and catheter-based or surgical thrombectomy [3]. Before ECMO was routinely established, patients with high-risk $\mathrm{PE}$ and severely deteriorated cardiac function received surgical embolectomy even during CPR with an acceptable outcome [4]. Though recent studies indicate better long-term outcome and lower PE-recurrence, surgery is merely used if thrombolysis fails or is contraindicated [5].

ESC guidelines recommend extracorporeal membrane oxygenation (ECMO) in critically ill, unstable PE patients as a bridge to other reperfusion techniques [3]. Though various studies on short-term outcome and mortality of PE treated with ECMO exist, little is known about the long-term outcome, quality of life (QoL), recovery of the right ventricle (RV) and cardiopulmonary function of these patients.

This study reports on short-term and long-term outcome of patients who received ECMO for acute, highrisk PE with emphasis on QoL and cardiopulmonary function.

\section{Methods}

\section{Patients}

We retrospectively analyzed our institutional ECMO database for all patients requiring ECMO from February 2007 to July 2020. Within these 13 years, 1876 ECMO runs have been entered into our database. Of these, 119 (6.3\%) patients received ECMO for acute high-risk PE and were included in this study. Seventy-three patients received ECMO with suspected $\mathrm{PE}$, which was later confirmed by $\mathrm{CT}$.

ECMO was indicated in patients with suspected or confirmed high-risk PE under CPR, in cardiogenic shock due to RV failure (increasing dose of epinephrine $>0.03 \mu \mathrm{g} / \mathrm{kg} / \mathrm{min}$ and noradrenalin $>0.05 \mu \mathrm{g} / \mathrm{kg} /$ min with a SBP $<90 \mathrm{mmHg}$ for $>1 \mathrm{~h}$ ), lactate levels above $3 \mathrm{mmol} / \mathrm{l}$, in severe respiratory failure (Horowitz index $(\mathrm{P} / \mathrm{F}$ ratio $)<100 \mathrm{mmHg}$ for $>12 \mathrm{~h})$ or if systemic thrombolysis or catheter-based thrombectomy failed and surgical thrombectomy was contraindicated.

The primary support type consisted of venoarterial (VA) ECMO. However, in patients with a predominant respiratory failure and high $\mathrm{pCO}_{2}$ levels and cardiogenic shock stabilized with high doses of vasopressors, venovenous (VV) ECMO was established. Our group already published a detailed description on what type of support to use [6].

ECMO was implemented by a team of trained doctors, perfusionists and nurses. All patients received standardized laboratory testing including troponin and brain natriuretic peptide, as well as echocardiography.

Our detailed ECMO management and equipment has been described previously $[7,8]$.

ECMO exclusion criteria consisted of known irreversible, severe brain damage, terminal malignancy, trauma with uncontrollable bleeding, unwitnessed circulatory arrest and an existing, credible declaration that the patient refuses to receive life-prolonging therapy. Age per se was no exclusion criterion.

Data were obtained via review of the institutional ECMO database and patients' medical records, including the electronic medical chart (Metavision V6.9.0.23 2019, iMDsoft, Düsseldorf, Germany).

\section{Follow-up and QoL analysis}

All patients willing to participate were invited for personal interviews.

Blood samples were evaluated for $\mathrm{N}$-terminal pro-brain natriuretic peptide levels (NT-proBNP) to unveil signs of heart failure.

A trained echocardiographer assessed RV-function via transthoracic echocardiography (TTE), including right ventricular end-diastolic diameter (RVEDD), tricuspid annular plane systolic excursion (TAPSE) and systolic pulmonary artery pressure (sPAP).

Pulmonary function test (PFT) (SentrySuite V3 10.2, Vyaire, Höchberg, Germany) and cardiopulmonary exercise testing (CPET) (Vyntus CPX, CareFusion, Höchberg, Germany) were performed if they were physically capable. Forced expiratory volume in $1 \mathrm{~s}$ (FEV1) and vital capacity (VC) were collected; the FEV1/VC ratio was calculated.

The CPET protocol (bicycle ergometer in upright position) consisted of $3 \mathrm{~min}$ of rest, followed by $3 \mathrm{~min}$ of unloaded pedalling at a rate of 50-60 rotations $/ \mathrm{min}$. and a ramp protocol using work rates (WR) of 5-20 Watts/ min. (according to the enquired fitness level) with a total exercise duration of 8-12 min. The following parameters were collected continuously over the whole study: heart rate, oxygen uptake $\left(\mathrm{VO}_{2}\right)$, carbon dioxide output $\left(\mathrm{VCO}_{2}\right)$, end-tidal $\mathrm{pO}_{2}$ and $\mathrm{pCO}_{2}\left(\right.$ PET- $\mathrm{pO}_{2}$; PET-CO $\left.{ }_{2}\right)$, 
respiratory rate, tidal volume. A capillary blood gas analysis was taken from the earlobe at rest and immediately after peak exercise. Calculated parameters consisted of: $\mathrm{O}_{2}$-pulse $\left(\mathrm{VO}_{2} / \mathrm{HR}\right)$, aerobic capacity $\left(\Delta \mathrm{VO}_{2} / \Delta \mathrm{WR}\right)$, minute ventilation (VE), $\mathrm{VE} / \mathrm{VCO}_{2}$ ratio (as slope and over time), breathing reserve (BR), respiratory exchange rate (RER), alveolar-arterial difference in partial pressures of oxygen $\left(\mathrm{AaDO}_{2}\right)$, arterial-to-end-tidal difference in partial pressures of carbon dioxide $\left[\mathrm{P}(\mathrm{a}-\mathrm{ET}) \mathrm{CO}_{2}\right]$. Peak oxygen consumption $\left(\right.$ Peak- $\left.\mathrm{VO}_{2}\right)$ is presented as $\mathrm{ml} \times \mathrm{min}^{-1} \times \mathrm{kg}^{-1}$ and \% predicted according to Wasserman [9].

QoL analysis was obtained using the EuroQol-5D-5L questionnaire (EQ-5D-5L), consisting of 2 parts:

The first part included health-related questions evaluating mobility, self-care, usual activities, pain/discomfort, or anxiety/depression. Each dimension comprises five levels: no, slight, moderate, severe, or extreme problems. The five dimensions result in a 5-digit number, describing the patient's health status (best imaginable health state: $1-1-1-1-1$; worst imaginable health state: $5-5-5-5-5$ ). It can be converted into an index value, ranging from maximally 1 to values lower than 0 .

The second part consisted of the EuroQol visual analogue scale (EQ-VAS) where the patient rates his health on a visual analogue scale (range $0-100 \%$ ). It represents a quantitative measure of health outcome reflecting the patient's own judgement.

The EQ-5D-5L index values and EQ-VAS of our study population were compared to an age-matched German reference population.

Six more questions were added: return-to-work status, groin problems due to cannulation, hospitalizations, or out-patient treatment due to cardiac or pulmonary problems, recurrence of deep lower leg thrombosis (DVT) or PE and New York Heart Association classification (NYHA).

Approval for this study was obtained from our institutional ethics board (Case number: 20-1905-104).

Individual patient consent was waived as this study was based on anonymized data from routine care.

\section{Statistical analysis}

Statistical analysis was performed with IBM SPSS Statistics 25 (IBM Corp., Armonk, NY). For data collection before import into SPSS, we used Excel for Windows (Microsoft Corp., Redmond, WA, USA).

Continuous data were presented as mean with standard deviation. Normal distribution was formally tested with the Shapiro-Wilk test.

Categorical data were presented as frequencies and percentages.
Comparison of continuous variables was performed using the Student's $t$ test and the Mann-Whitney $U$ test.

Categorical variables were compared using the Chisquare test. A $p$ value $<0.05$ was considered statistically significant.

To identify predictors of survival to discharge, several parameters were analyzed including their odds ratios (OR) in a univariate fashion using regression analysis.

Kaplan-Meier survival analysis was used to estimate the proportion of survivors and visualized in survival curves.

Missing data were deleted listwise.

\section{Results \\ Study population}

From February 2007 to July 2020, 119 patients underwent ECMO implantation for high-risk PE. The majority of patients were placed on VA ECMO (87 patients, 73.1\%), about one-quarter on VV ECMO (32 patients, 26.9\%). Mean age was $51 \pm 15$ years (min 16 years; max 79 years). Most patients were male $(n=69.6 \%)$. Patient characteristics are displayed in Table 1.

Of the 80 patients (67\%) receiving CPR, 52 (65\%) were placed on ECMO under CPR, the remaining 28 (35\%) after returned spontaneous circulation but persisting shock and RV failure less than $12 \mathrm{~h}$ prior to ECMO.

Cannulation was performed at our center $(n=64$, $53.8 \%)$ or at the referring hospital $(n=45,37.8 \%)$. Ten (8.4\%) patients were cannulated out of hospital.

Fifty patients $(42 \%)$ received thrombolytic therapy, 17 patients $(14.3 \%)$ interventional or surgical thrombectomy prior to/on ECMO. The remaining patients $(n=52$, $43.7 \%)$ were treated with therapeutic anticoagulation alone.

\section{Short-term outcome}

Successful weaning was achieved in 61 patients (51.3\%).

Another 7 patients (6\%) died during further hospital stay, resulting in a survival-to-discharge rate of $45.4 \%$ ( $n$ $=54$ ). Leading cause of death was brain death following prolonged CPR.

Causes of death on ECMO are depicted in Table 2.

Survival-to-discharge rates did not differ significantly for patients treated with thrombolysis, interventional/ surgical thrombectomy or anticoagulation alone $(p$ $=0.76$ ).

Survivors had a longer ventilation time $(400.6 \pm 343.8 \mathrm{~h}$ vs. $203.52 \pm 311.3 \mathrm{~h} ; \mathrm{p}=0.001)$ and ECMO duration (7.8 \pm 7.7 days vs. $5.8 \pm 8.6$ days; $\mathrm{p}=0.023$ ) compared to non-survivors.

Survivors also had a longer ICU (25 \pm 21 days vs. $9.5 \pm 12.5 ; p<0.001$ ) and overall hospital stay $(33 \pm 25.5$ days vs. $9.5 \pm 12.5$ days; $p<0.001)$. 
Table 1 Demographic data

\begin{tabular}{|c|c|c|c|c|}
\hline & All patients $(n=119)$ & Survivors $(n=54)$ & $\begin{array}{l}\text { Non-survivors ( } n \\
=65 \text { ) }\end{array}$ & $p$ value \\
\hline Age (years) & $50.9 \pm 14.8$ & $49 \pm 15$ & $52.5 \pm 14.5$ & 0.196 \\
\hline Male & $69(57.9 \%)$ & $30(55.6 \%)$ & $39(60 \%)$ & 0.625 \\
\hline $\operatorname{BMI}\left(\mathrm{kg} / \mathrm{m}^{2}\right)$ & $29 \pm 14$ & $30.3 \pm 7.5$ & $32.3 \pm 10$ & 0.246 \\
\hline Pre-lactate (mmol/l) & $9.6 \pm 6.9$ & $6.9 \pm 5.3$ & $14.1 \pm 7.2$ & $<0.001$ \\
\hline Pre-norepinephrine ( $\mathrm{\mu g} / \mathrm{kg} / \mathrm{min})$ & $0.5 \pm 0.7$ & $0.6 \pm 0.5$ & $0.5 \pm 0.5$ & 0.111 \\
\hline Pre-epinephrine ( $\mu \mathrm{g} / \mathrm{kg} / \mathrm{min})$ & $0.8 \pm 1.2$ & $0.14 \pm 0.3$ & $0.2 \pm 0.3$ & 0.04 \\
\hline Pre-MAP $(\mathrm{mmHg})$ & $55 \pm 17$ & $61 \pm 15$ & $44 \pm 16$ & $<0.001$ \\
\hline Pre-pH & $7.2 \pm 0.17$ & $7.2 \pm 0.15$ & $7.05 \pm 0.2$ & 0.005 \\
\hline Pre-prothrombin time (\%) & $60 \pm 27$ & $64 \pm 24$ & $51 \pm 27$ & 0.007 \\
\hline Pre-D-dimer (mg/l) & $16 \pm 3.8$ & $21.3 \pm 13.3$ & $28.4 \pm 12.9$ & 0.269 \\
\hline Peak NSE-level ( $\mu \mathrm{g} / \mathrm{l})$ & $146 \pm 171$ & $53 \pm 32$ & $214 \pm 208$ & 0.002 \\
\hline Peak fHb (mg/l) & $489 \pm 554$ & $278 \pm 388$ & $578 \pm 642$ & 0.007 \\
\hline Preimplant CPR & $80(67.2 \%)$ & 31 (57.4\%) & 49 (75.4\%) & 0.039 \\
\hline Duration of CPR (min) & $55.1 \pm 32.7$ & $46.3 \pm 27.6$ & $58.9 \pm 34.3$ & 0.158 \\
\hline Average ECMO support (days) & $6.6 \pm 8.2$ & $7.6 \pm 7.7$ & $5.8 \pm 8.6$ & $<0.001$ \\
\hline ICU stay (days) & $16.6 \pm 18.4$ & $25.2 \pm 20.6$ & $9.5 \pm 12.5$ & $<0.001$ \\
\hline Overall hospital stay (days) & $20.2 \pm 22.7$ & $33 \pm 25.5$ & $9.5 \pm 12.5$ & $<0.001$ \\
\hline
\end{tabular}

Statistically significant $p$-values are reported in bold

$B M I$ body mass index; MAP mean arterial pressure; NSE neuron-specific enolase; $f H b$ free plasma hemoglobin; $C P R$ cardiopulmonary resuscitation; ICU intensive care unit

Table 2 Causes of death on ECMO

\begin{tabular}{ll}
\hline Death on ECMO & $\boldsymbol{n = 5 8}$ \\
\hline Cerebral & $30(51.7 \%)$ \\
LCO & $7(12.1 \%)$ \\
MOF & $10(17.2 \%)$ \\
Sepsis & $4(6.9 \%)$ \\
Withdrawal of therapy & $4(6.9 \%)$ \\
Miscellaneous & $3(5.2 \%)$ \\
\hline
\end{tabular}

LCO low cardiac output; MOF multi-organ failure

Patients requiring CPR prior to ECMO had a significantly lower survival-to-discharge rate with $38.8 \%$ ( $p$ $=0.038)$.

\section{Parameters predictive of survival}

Parameters associated with higher survival-to-discharge rates were less acidotic pH-levels [OR 43.8 (increase/1 unit); 95\% CI 3.2-595; $p=0.005$ ], higher mean arterial pressure [MAP; OR 1.07(increase /1 mmHg); 95\% CI $1.04-1.1 ; p<0.001]$ and higher prothrombin time [OR 1.02 (increase/1 unit); 95\% CI 1.0-1.04; $p=0.007$ ] prior to ECMO implantation.

CPR prior to ECMO (OR 2.72; 95\% CI 1.044.96; $p=0.039$ ), elevated lactate levels [OR 1.13 (increase/1 mmol/l); 95\% CI 0.98-1.31; $p<0.001]$ and epinephrine dose [OR 1.89 (increase $/ 1 \mu \mathrm{g} / \mathrm{kg} / \mathrm{min}$ ); 95\%
CI $0.867-4.14 ; p=0.04$ ] before ECMO treatment were associated with lower survival-to-discharge rates, as was the need for hemodialysis during hospital stay (OR 2.19; 95\% CI 1.04-4.63; $p=0.039$ ).

None of the treatment modalities (in detail: surgical thrombectomy, thrombolysis, VA or VV support) could be identified as predictive factor for survival to discharge $(p=0.76)$.

\section{Long-term outcome}

The 54 patients $(45.4 \%$ of all patients) surviving to discharge were followed for 21.5 months (median 3 months); nine deceased during a mean follow-up time of 31.4 months (median 2.5 months; causes of death: 2 terminal malignancies, 3 recurrent PE, 4 unknown). 45 patients (37.8\% of all patients) were available for followup. Kaplan-Meier survival curve is depicted in Fig. 1.

Six patients were lost during follow-up. Five patients refused to participate in this study. At a median followup of 54.5 months (25-73; $56 \pm 38$ months), 34 patients $(75.5 \% ; 34 / 45)$ patients answered the EQ-5D-5L, but only $51 \%(20 / 34)$ attended the follow-up examinations at our clinic. Follow-up is depicted in Fig. 2.

Of the interviewed patients, 11 (33.3\%) had returned to work (average working hours: $36.2 \pm 12.5 \mathrm{~h} /$ per week), 15 (45.4\%) had retired from work early. 


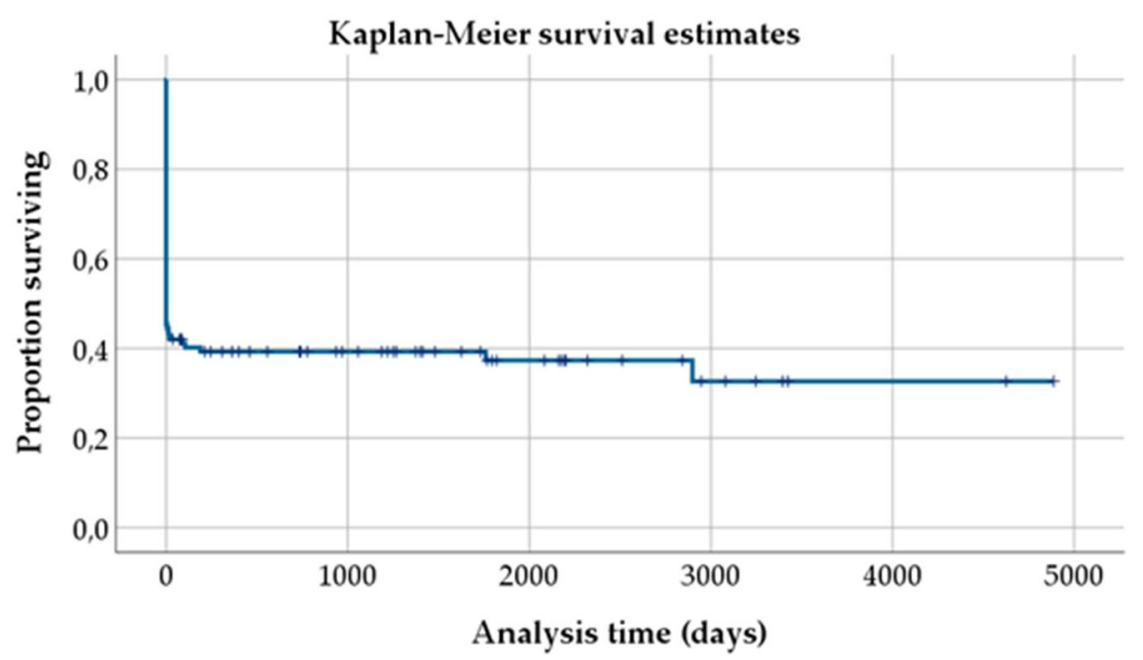

Fig. 1 Kaplan-Meier estimation of survival over follow-up time. Figure 1 shows the overall survival (in days) after onset of pulmonary embolism until the time of follow-up

Ongoing symptoms of polyneuropathy were reported by three, recurrent DVT despite adequate anticoagulation with NOAC by two patients.

None of the patients reported groin problems after cannulation or experienced recurrent PE.

\section{Structured interviews and QoL}

No limitations in motoractivity and mobility were stated in $73.5 \%$ ( 25 patients). Of 9 patients reporting moderate or severe problems, two had suffered irreversible spinal cord injury and were bound to a wheelchair; another 3 were hemiplegic due to cerebral insult. The remaining 2 patients suffered from joint pain. None of the limitations were due to PE or ECMO.

Twenty-two patients (65\%) could handle their usual activities without or with only slight problems, 18 patients (53\%) reported persistent pain and discomfort, mainly due to critical illness polyneuropathy.

Anxiety or depression was reported by 10 patients (29.4\%).

The mean EQ5D5L index of our study population was significantly reduced compared to an age-matched German reference population (EQ5D5L index study population $=0.74 \pm 0.3$; vs. German reference population $=0.9 \pm 0.04 ; p<0.01$ ). The EQ-VAS value also differed significantly between the groups (EQ-VAS study group $=64 \pm 18 \%$; vs. EQ-VAS German reference population $=77.1 \pm 6 \% ; p<0.01)[10]$. Results are visualized in Fig. 3.

The mean EQ5D5L index showed no difference between the 20 patients who attended the follow-up examination and the 14 patients who answered the questionnaire at home (EQ5D5L index exam group $0.7 \pm 0.3$ vs. at home group $0.79 \pm 0.2 ; p=0.73$ ), while the mean EQ-VAS showed a trend to better performance in the exam group (EQ-VAS exam group $68 \pm 19 \%$ vs. $58 \pm 15 \% ; p=0.064)$.

Chest pain, dyspnea, vertigo or severe cardiopulmonary limitations were denied by 22 patients (64.7\%), while 7 patients (20.5\%) expressed limited exercise tolerance and dyspnea according NYHA Stadium II, 5 (14.7\%) even NYHA III.

\section{Echocardiography, pulmonary function and cardiopulmonary exercise test}

The entire group of 20 patients who attended our clinic for follow-up received TTE and PFT, while only 14 were willing and able to perform CPET. Of those, one patient was excluded from analysis due to ventilatory limitation caused by a pre-existing severe chronic obstructive pulmonary disease (FEV1 33\% predicted, BR 2\%, peak- $\mathrm{VO}_{2}$ $53 \%$ predicted). The results of the remaining patients are displayed in Table 3.

There were no echocardiographic signs of relevant residual right heart strain or pulmonary hypertension, supported by NT-proBNP levels in the age-adjusted normal range for all patients. PFT revealed slightly reduced mean FVC, FEV1, and DLCO, reflecting mainly outliers with pre-existing lung diseases. None of the patients needed oxygen at rest. Hyperventilation at rest, which might reflect residual pulmonary vascular obstruction, was only evident in 2 patients below a $\mathrm{pCO}_{2}$ of $30 \mathrm{mmHg}$ (28.8 and $29.4 \mathrm{mmHg}$ ). However, those patients had a Peak- $\mathrm{VO}_{2}$ of 75 and $95 \%$ predicted without further 


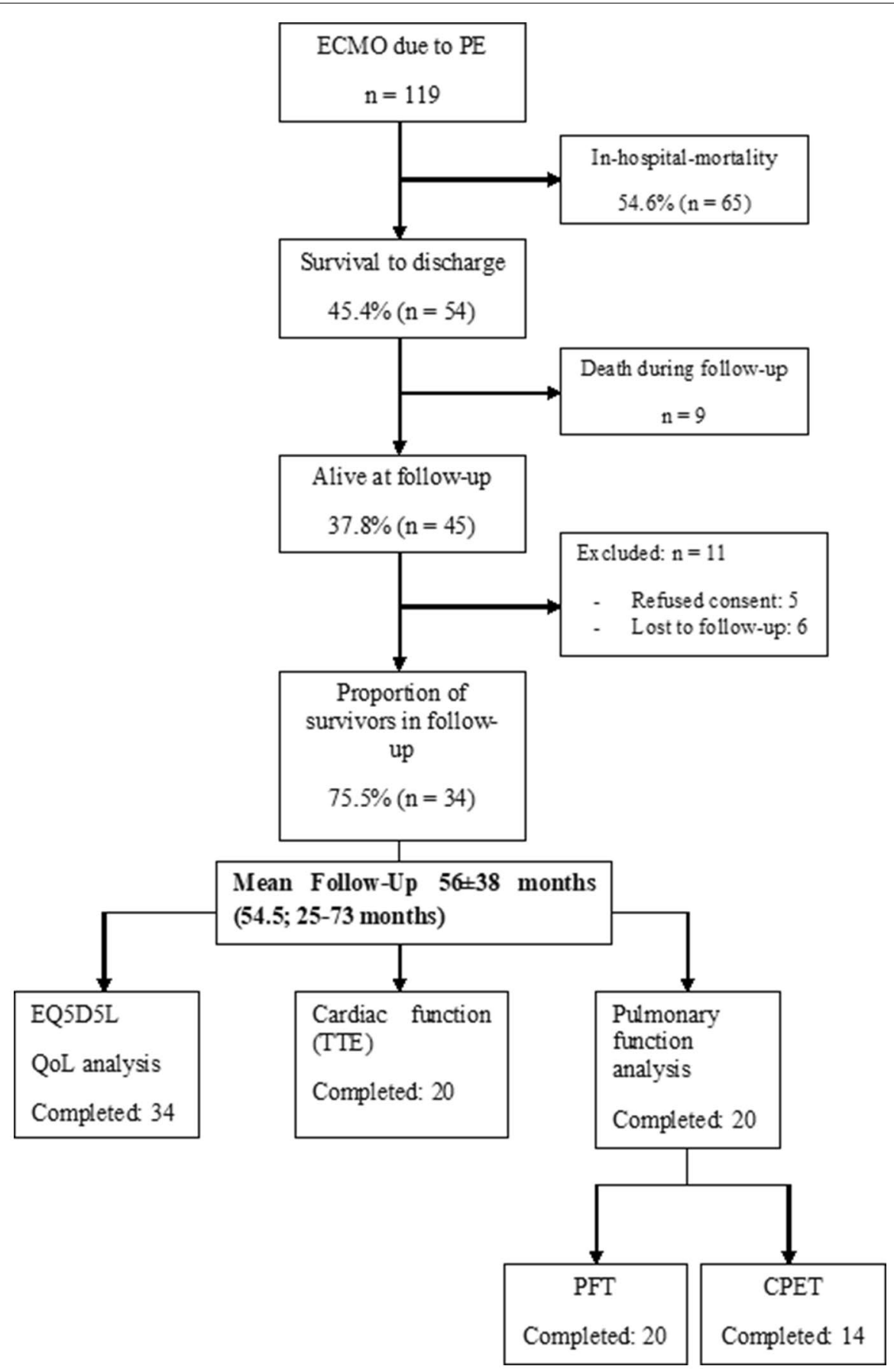

Fig. 2 Flowchart of the recruitment and follow-up process. Figure 2 depicts the follow-up process from onset of the disease until follow-up

evidence for chronic thromboembolic pulmonary hypertension (CTEPH).

On CPET, the mean maximal WR and Peak- $\mathrm{VO}_{2}$ were slightly reduced. However, only 5 patients had a Peak$\mathrm{VO}_{2}$ below $75 \%$ of predicted, and none of them showed a typical pattern of cardio-circulatory limitation. The good mean exercise performance of patients who were able to undergo a CPET study is further supported by normal mean values for the $\mathrm{VE} / \mathrm{VCO}_{2}$ slope, aerobic capacity and gas exchange parameters (see Table 3 ). 


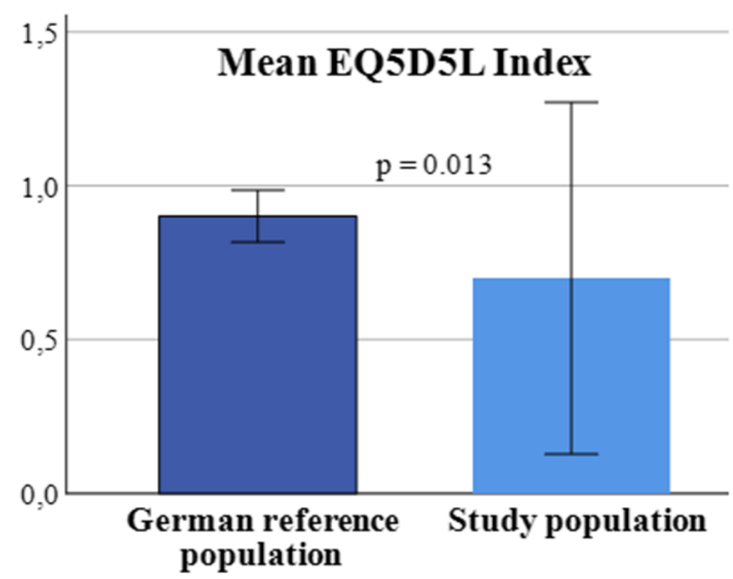

(a)

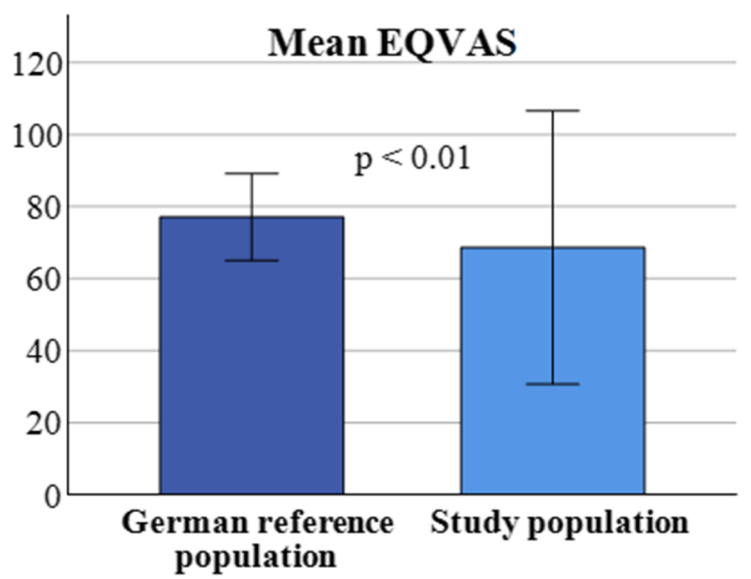

(b)

Fig. 3 QoL comparison between study group and German reference population: a mean EQ5D5L index; b mean EQ-VAS. Figure 3 visualizes the differences in objective (EQ5D5L index) and subjective quality of life (EQ-VAS) of the study population and a German reference population

Table 3 Echocardiography, pulmonary function and cardiopulmonary exercise test at follow-up

\begin{tabular}{|c|c|c|}
\hline Parameter $(n)$ & Mean \pm SD & Range (min.-max.) \\
\hline \multicolumn{3}{|l|}{ Echocardiography (20 patients) } \\
\hline Right atrial area, $\mathrm{cm}^{2}$ & $16.0 \pm 3.6$ & $8.0-22.0$ \\
\hline RVEDD, mm & $32.9 \pm 5.6$ & $22.0-44.0$ \\
\hline TAPSE, mm & $23.2 \pm 5.8$ & $17.0-38.0$ \\
\hline Systolic PAP, mmHg (15 patients) & $19.3 \pm 4.8$ & $13.0-30.0$ \\
\hline \multicolumn{3}{|c|}{ Pulmonary function test and capillary blood gas analysis (20 patients) } \\
\hline Vital capacity, \% predicted & $83.1 \pm 16.1$ & $51.0-105.0$ \\
\hline FEV1, \% predicted & $80.5 \pm 19.8$ & $33.0-105.0$ \\
\hline DLCO, \% predicted & $73.1 \pm 22.1$ & $30.0-97.0$ \\
\hline $\mathrm{pCO}_{2}, \mathrm{mmHg}$ & $36.0 \pm 4.0$ & $28.8-42.7$ \\
\hline Oxygen saturation, $\%$ on room air & $95.8 \pm 1.5$ & $94.0-98.0$ \\
\hline \multicolumn{3}{|l|}{ Cardiopulmonary exercise test (13 patients) } \\
\hline Maximum work rate, $\mathrm{W}$ & $125.8 \pm 52.8$ & $52.0-221.0$ \\
\hline Maximum work rate, $\%$ predicted & $82.8 \pm 23.1$ & $41.0-118.0$ \\
\hline Peak-VO ${ }_{2}, \mathrm{ml} \times \min ^{-1} \times \mathrm{kg}^{-1}$ & $19.2 \pm 8.3$ & $9.3-34.0$ \\
\hline Peak- $\mathrm{VO}_{2}, \%$ predicted & $76.3 \pm 16.1$ & $44.0-102.0$ \\
\hline RER max. & $1.4 \pm 0.2$ & $1.1-1.9$ \\
\hline Breathing reserve, \% & $44.4 \pm 14.5$ & $21.0-70.0$ \\
\hline VENCO ${ }_{2}$ slope & $28.7 \pm 4.9$ & $19.5-39.1$ \\
\hline$\Delta \mathrm{VO}_{2} / \Delta \mathrm{WR}$ slope, $\mathrm{ml} \times \mathrm{min}^{-1} \times \mathrm{W}^{-1}$ & $9.6 \pm 1.0$ & $7.1-11.2$ \\
\hline $\mathrm{P}(\mathrm{a}-\mathrm{ET}) \mathrm{CO}_{2}, \mathrm{mmHg}$ & $4.5 \pm 2.0$ & $0.3-6.9$ \\
\hline $\mathrm{AaDO}_{2}, \mathrm{mmHg}$ & $29.2 \pm 7.0$ & $19.9-40.1$ \\
\hline
\end{tabular}

$\mathrm{AaDO}_{2}$ alveolar-arterial difference in partial pressures of oxygen; DLCO diffusion capacity of the lung for carbon monoxide; FEV1 forced end-expiratory volume in one second; $P A P$ pulmonary arterial pressure; $P(a-E T) C O_{2}$ arterial to end-tidal difference in partial pressures of $\mathrm{CO}_{2} ; R E R$ respiratory exchange rate; $R V E D D$ right ventricular end-diastolic diameter; TAPSE tricuspid anterior plane systolic excursion 


\section{Discussion}

To our knowledge, this is the largest single-center study analyzing the long-term outcome of patients requiring ECMO for acute high-risk PE, comprising 119 patients and covering 13 years of our institutional experience. 34 patients were evaluated for long-term outcome and QoL. Cardiopulmonary function and exercise capacity were examined in 20 patients.

For patients suffering from this severe disease with high morbidity and mortality, the hospital discharge rates in literature vary between 62, 70.1 and even 100\% in patients receiving ECMO with anticoagulation treatment only $[11,12]$. However, those reports investigated smaller cohorts (max. 21 patients) and included case reports which are prone to publication bias. More recent research with comparable study design was in line with our results, displaying survival-to-discharge rates of 44.4 and $38.5 \%[13,14]$.

Our survival to discharge was $45.4 \%$, overall survival at a mean follow-up of 4.5 years and a maximum of 13 years was $37.8 \%$. It should be emphasized that most of our patients received ECMO during or after CPR.

Our findings are also supported by the most recent data of the international ELSO registry $[6,15]$.

CPR prior to ECMO was necessary in $67.2 \%$ of our patients and associated with an unfavorable prognosis, as reported by Corsi and Chen $[13,16]$.

$\mathrm{CTEPH}$, defined as a mean pulmonary artery pressure $>25 \mathrm{mmHg}$ and a normal wedge pressure on right heart catheterization at rest due to residual pulmonary artery obstruction on chronic (>3 months) therapeutic anticoagulation, is described with an incidence of $4 \%$ in PE survivors and decreases QoL and exercise capacity [17]. Even if we did not perform ventilation/perfusion scanning of the lung, given the findings of TTE, PFT, and CPET, it is unlikely that one of our patients who attended our center for follow-up suffered from CTEPH or relevant residual $\mathrm{PE}$.

To our knowledge, no literature examining RV-function and cardiopulmonary function after PE treated with ECMO exists to date. Sista and Albaghdadi et al. performed research concerning these outcome variables in PE patients without ECMO treatment:

Sista reported a pooled prevalence of RV dysfunction on echocardiography of $18.1 \%$ after 6 months of follow-up, and a mean 6-min-walk distance of $415 \mathrm{~m}$ at 12 months [18]. Albaghdadi used echocardiography and CPET to evaluate cardiopulmonary performance and found RV dilation or dysfunction in more than one-third of PE survivors. Sixty percent showed a reduced peak$\mathrm{VO}_{2}$ after 1 and 6 months [19]. However, this study did not include ECMO as treatment modality and patients were limited by deconditioning rather than residual PE or CTEPH.

To analyze our study population for signs of CTEPH, we assessed cardiopulmonary function and exercise capacity: after a mean follow-up of 53 months none of the patients had signs of RV dysfunction or pulmonary hypertension. All but 5 patients showed good exercise capacity with a Peak- $\mathrm{VO}_{2}$ of at least $75 \%$ predicted, including $8(57 \%)$ patients who were resuscitated prior to ECMO.

In Albaghdadi's and our study, there was no clear relationship between impaired exercise capacity and reduced RV-function or reduced pulmonary capacity. As data concerning exercise capacity prior to the event are lacking, it is impossible to refer to pre-existing conditions. However, exercise intolerance could be attributed to clearly pre-existing conditions like severe COPD. In other words, it was related rather to general deconditioning as in Albaghdadi's experience.

Their data are however contradictory to our study regarding echocardiography on follow-up. No severe RV dysfunction or relevant pulmonary hypertension was noted in our patient population. Possible explanations for this discrepancy are a protective effect of ECMO on RV through workload reduction and better gas exchange, or different anticoagulation and medical treatment, even if selection bias is the most likely reason.

As a limitation of our study, only 20 of 34 eligible patients presented to our hospital for personal re-assessment, and only 14 were able and willing to perform a CPET study. Therefore, a considerable selection bias must be considered.

When evaluating new, invasive and expensive therapeutic strategies, not only survival, but also QoL has a high priority. Wenger et al. described QoL as 'an individual's perceptions of his or her functioning and well-being in different domains of life' [20].

Only few studies concerning QoL after ECMO in general exist so far.

Corsi et al. interviewed 7 patients at a mean follow-up of 19 months post-hospital discharge using the SF-36 and found QoL impaired compared to a sex- and agematched control [13]. Similar findings are reported by Sertic, with patients strongly limited concerning physical, but preserved mental health [21].

Hodgson's group reported on QoL in ECMO for cardiogenic shock or respiratory failure, showing reduced QoL compared to the reference population with about $25 \%$ return-to-work status, similarly to our study (returnto-work status 34.7\%) [22, 23].

A Norwegian study evaluated QoL of 213 patients after PE without ECMO treatment: the EQ-5D-5L index was 
0.8 whereas EQ-VAS was $67 \%$ and was slightly reduced compared to an age-matched reference population [24]. As information about the underlying treatments or the number of patients receiving CPR in their study is lacking, a direct comparison to our results is highly difficult and no conclusions can be drawn concerning the impact of ECMO treatment on QoL of PE patients. However, the disease itself and prolonged ICU stay seem to be determining factors [25].

To assess the complex, multivariable and completely subjective entity of QoL, we chose the EQ-5D-5L questionnaire because it is a scientifically proven, simple, reliable test which includes physical, functional and psychological aspects.

According to EQ-5D-5L, QoL in our study population was reduced compared to a German reference population $[26,27]$. The patients who answered the questionnaire at home showed significantly better index values while estimating their own QoL with EQ-VAS significantly worse than the examined patients. The reduced values of the self-estimated EQ-VAS of the patients at home might explain why these patients did not consent to personal interviews at our clinic. The ongoing Corona pandemic during the study period might also have contributed to a limited willingness to visit our clinic in person.

Therefore, our findings concerning QoL are consistent with previously published literature. To compare QoL in PE patients with and without ECMO treatment properly, further prospective trials are needed.

\section{Limitations}

The study's limitations lie in the retrospective design, reporting a single-center experience analyzing long-term functional follow-up after severe PE and ECMO with a relatively small study population. As it was our primary intention to evaluate the functional capacity of these patients, we did not divide the results according to $\mathrm{VV}$ and VA ECMO. The small sample size of VA and VV ECMO patients would have made proper comparison impossible. Still, this must be considered as limitation. Only $51 \%$ of patients received TTE and PFT or CPET at our clinic, therefore, a strong selection bias must be considered. Because of the small sample size, the results cannot be generalized and further studies with a larger follow-up group are much needed. As comparative QoL data are lacking before the event, it is uncertain if QoL was impaired before or because of ECMO treatment.

\section{Conclusions}

ECMO should be considered in high-risk PE with cardiogenic shock or severe respiratory failure if other therapy modalities are not applicable. Survivors seem to recover well in the long term with an acceptable QoL and good overall cardiopulmonary function. Further research with larger patient cohorts is needed to underline these results.

\section{Abbreviations}

$\mathrm{AaDO}_{2}$ : Alveolar-arterial difference in partial pressures of oxygen; BR: Breathing reserve; COPD: Chronic obstructive pulmonary disease; CPET: Cardiopulmonary exercise testing; CPR: Cardiopulmonary resuscitation; CT-scan: Computed tomography scan; CTEPH: Chronic thromboembolic pulmonary hypertension; DLCO: Diffusion capacity of the lung for carbon monoxide; DVT: Deep vein thrombosis; ECMO: Extracorporeal membrane oxygenation; EQ5D-5L: EuroQol-5D-5L questionnaire; EQ-VAS: EuroQol visual analogue scale; ESC: European Society of Cardiology; FEV F $_{1}$ Forced end-expiratory volume in one second; FVC: Forced vital capacity; ICU: Intensive care unit; LCO: Low cardiac output; LDH: Lactate-dehydrogenase; LV function: Left ventricular function; MAP: Mean arterial pressure; MOF: Multi-organ failure; NOAC: Novel oral anticoagulants; NSE: Neuron-specific enolase; NT-proBNP: N-terminal pro-brain natriuretic peptide; NYHA: New York Heart Association; OR: Odds ratio; $\mathrm{P}(\mathrm{a}-\mathrm{ET}) \mathrm{CO}_{2}$ : Arterial to end-tidal difference in partial pressures of $\mathrm{CO}_{2} ; \mathrm{PE}$ : Pulmonary embolism; Peak- $\mathrm{VO}_{2}$ : Peak oxygen consumption; Peak predicted$\mathrm{VO}_{2}$ : Predicted peak oxygen consumption; $\mathrm{PET}-\mathrm{pCO}_{2}$ : End-tidal carbon dioxide; PET- $\mathrm{pO}_{2}$ : End-tidal oxygen; $\mathrm{P} / \mathrm{F}$ ratio: Horowitz index; PFT: Pulmonary function testing; fHb: Free plasma hemoglobin; QoL: Quality of life; RER: Respiratory exchange rate; RV: Right ventricle; RVEDD: Right ventricular end-diastolic diameter; SBP: Systolic blood pressure; SF-36: Short Form-36 health survey; SPAP: Systolic pulmonary artery pressure; TAPSE: Tricuspid annular plane systolic excursion; TTE: Transthoracic echocardiography; VA: Venoarterial; VC: Vital capacity; W: Veno-venous.

\section{Acknowledgements}

Not applicable.

\section{Authors' contributions}

AS contributed toward conceptualization, data curation, formal analysis, investigation, project administration, methodology, and writing —original draft. AP contributed toward conceptualization and data curation. SB, ML, DL, JL, AT and CS contributed toward writing - review and editing. DC and TJL contributed toward conceptualization, methodology, supervision, writing —original draft, review, and editing. All authors read and approved the final manuscript.

Funding

Open Access funding enabled and organized by Projekt DEAL.

Availability of data and materials

The datasets used and/or analyzed during the current study are available from the corresponding author on reasonable request.

\section{Declarations}

\section{Ethics approval and consent to participate}

Approval for this study was obtained from the ethics board of the University of Regensburg (Case number: 20-1905-104). The requirement for individual patient consent was waived as this study was based on anonymized data from routine care.

\section{Consent for publication \\ Not applicable.}

\section{Competing interests}

The authors declare that they have no competing interests.

\section{Author details}

${ }^{1}$ Department of Cardiothoracic Surgery, University Medical Center Regensburg, Franz-Josef-Strauss-Allee 11, 93053 Regensburg, Germany. ${ }^{2}$ Department of Anesthesiology, University Medical Center Regensburg, Franz-Josef-Strauss-Allee 11, 93053 Regensburg, Germany. 
${ }^{3}$ Department of Internal Medicine II, University Medical Center Regensburg, Franz-Josef-Strauss-Allee 11, 93053 Regensburg, Germany.

Received: 12 August 2021 Accepted: 15 December 2021

Published online: 24 December 2021

\section{References}

1. Cohen AT, Agnelli G, Anderson FA, Arcelus Jl, Bergqvist D, Brecht JG, et al. Venous thromboembolism (VTE) in Europe. The number of VTE events and associated morbidity and mortality. Thromb Haemost. 2007:98(4):756-64.

2. Kasper W, Konstantinides S, Geibel A, Olschewski M, Heinrich F, Grosser $\mathrm{KD}$, et al. Management strategies and determinants of outcome in acute major pulmonary embolism: results of a multicenter registry. J Am Coll Cardiol. 1997;30(5):1165-71.

3. Konstantinides SV, Meyer G, Becattini C, Bueno H, Geersing G-J, Harjola V-P, et al. 2019 ESC Guidelines for the diagnosis and management of acute pulmonary embolism developed in collaboration with the European Respiratory Society (ERS). Eur Heart J. 2020;41 (4):543-603.

4. Schmid C, Zietlow S, Wagner TO, Laas J, Borst HG. Fulminant pulmonary embolism: symptoms, diagnostics, operative technique, and results. Ann Thorac Surg. 1991:52(5):1102-7.

5. Lee T, Itagaki S, Chiang YP, Egorova NN, Adams DH, Chikwe J. Survival and recurrence after acute pulmonary embolism treated with pulmonary embolectomy or thrombolysis in New York State, 1999 to 2013. J Thorac Cardiovasc Surg. 2018;155(3):1084-1090.e12.

6. Kmiec L, Philipp A, Floerchinger B, Lubnow M, Unterbuchner C, Creutzenberg $\mathrm{M}$, et al. Extracorporeal membrane oxygenation for massive pulmonary embolism as bridge to therapy. ASAIO J. 2020;66(2):146-52.

7. Schmid C, Philipp A, Hilker M, Rupprecht L, Arlt M, Keyser A, et al. Venovenous extracorporeal membrane oxygenation for acute lung failure in adults. J Heart Lung Transplant. 2012;31(1):9-15.

8. Schopka S, Philipp A, Hilker M, Müller T, Zimmermann M, Arlt M, et al. Clinical course and long-term outcome following venoarterial extracorporeal life support-facilitated interhospital transfer of patients with circulatory failure. Resuscitation. 2015;93:53-7.

9. Hansen JE, Sue DY, Wasserman K. Predicted values for clinical exercise testing. Am Rev Respir Dis. 1984;129(2 Pt 2):S49-55.

10. Ludwig K, von der Schulenburg J-MG, Greiner W. German value set for the EQ-5D-5L. Pharmacoeconomics. 2018;36(6):663-74.

11. Maggio P, Hemmila M, Haft J, Bartlett R. Extracorporeal life support for massive pulmonary embolism. J Trauma. 2007:62(3):570-6.

12. Yusuff HO, Zochios V, Vuylsteke A. Extracorporeal membrane oxygenation in acute massive pulmonary embolism: a systematic review. Perfusion. 2015;30(8):611-6.

13. Corsi F, Lebreton G, Bréchot N, Hekimian G, Nieszkowska A, Trouillet J-L, et al. Life-threatening massive pulmonary embolism rescued by venoarterial-extracorporeal membrane oxygenation. Crit Care. 2017;21(1):76.

14. Meneveau N, Guillon B, Planquette B, Piton G, Kimmoun A, Gaide-Chevronnay $\mathrm{L}$, et al. Outcomes after extracorporeal membrane oxygenation for the treatment of high-risk pulmonary embolism: a multicentre series of 52 cases. Eur Heart J. 2018;39(47):4196-204.

15. Organization ELS. ECMO Registry of the Extracorporeal Life Support Organization (ELSO). Ann Arbor: Michigan; 2020.

16. Chen $Y-Y$, Chen $Y-C$, Wu C-C, Yen H-T, Huang K-R, Sheu J-J, et al. Clinical course and outcome of patients with acute pulmonary embolism rescued by veno-arterial extracorporeal membrane oxygenation: a retrospective review of 21 cases. J Cardiothorac Surg. 2020;15(1):295.

17. Klok FA, van der Hulle T, den Exter PL, Lankeit M, Huisman MV, Konstantinides $S$. The post-PE syndrome: a new concept for chronic complications of pulmonary embolism. Blood Rev. 2014;28(6):221-6.

18. Sista AK, Miller LE, Kahn SR, Kline JA. Persistent right ventricular dysfunction, functional capacity limitation, exercise intolerance, and quality of life impairment following pulmonary embolism: systematic review with meta-analysis. Vasc Med. 2017;22(1):37-43.

19. Albaghdadi MS, Dudzinski DM, Giordano N, Kabrhel C, Ghoshhajra B, Jaff $M R$, et al. Cardiopulmonary exercise testing in patients following massive and submassive pulmonary embolism. J Am Heart Assoc. 2018. https:// doi.org/10.1161/JAHA.117.006841.
20. Wenger NK, Mattson ME, Furberg CD, Elinson J. Assessment of quality of life in clinical trials of cardiovascular therapies. Am J Cardiol. 1984;54(7):908-13.

21. Sertic F, Diagne D, Chavez L, Richards T, Berg A, Acker M, et al. Mid-term outcomes with the use of extracorporeal membrane oxygenation for cardiopulmonary failure secondary to massive pulmonary embolism. Eur J Cardiothorac Surg. 2020;58(5):923-31.

22. Camboni D, Philipp A, Rottenkolber V, Zerdzitzki M, Holzamer A, Floerchinger $B$, et al. Long-term survival and quality of life after extracorporeal life support: a 10-year report. Eur J Cardiothorac Surg. 2017;52(2):241-7.

23. Hodgson CL, Hayes K, Everard T, Nichol A, Davies AR, Bailey MJ, et al. Long-term quality of life in patients with acute respiratory distress syndrome requiring extracorporeal membrane oxygenation for refractory hypoxaemia. Crit Care. 2012;16(5):R202.

24. Tavoly M, Utne KK, Jelsness-Jørgensen L-P, Wik HS, Klok FA, Sandset PM, et al. Health-related quality of life after pulmonary embolism: a crosssectional study. BMJ Open. 2016;6(11):e013086.

25. Gaudino M, Girola F, Piscitelli M, Martinelli L, Anselmi A, Della Vella C, et al. Long-term survival and quality of life of patients with prolonged postoperative intensive care unit stay: unmasking an apparent success. J Thorac Cardiovasc Surg. 2007;134(2):465-9.

26. Szende A, Janssen B, Cabases J, editors. Self-reported population health: an international perspective based on EQ-5D. Dordrecht: Springer Netherlands; 2014

27. Grochtdreis T, Dams J, König H-H, Konnopka A. Health-related quality of life measured with the EQ-5D-5L: estimation of normative index values based on a representative German population sample and value set. Eur J Health Econ. 2019;20(6):933-44.

\section{Publisher's Note}

Springer Nature remains neutral with regard to jurisdictional claims in published maps and institutional affiliations.

\section{Submit your manuscript to a SpringerOpen ${ }^{\circ}$ journal and benefit from:}

- Convenient online submission

- Rigorous peer review

- Open access: articles freely available online

- High visibility within the field

- Retaining the copyright to your article

Submit your next manuscript at $\boldsymbol{\nabla}$ springeropen.com 